\title{
Erosion-corrosion behavior of X65 carbon steel in oilfield formation water
}

\author{
Jingbo Liu ${ }^{1,2}$, Jihui Wang ${ }^{1,2, *}$, Wenbin $\mathrm{Hu}^{2}$ \\ ${ }^{1}$ State Key Laboratory of Hydraulic Engineering Simulation and Safety, Tianjin University, Tianjin \\ 300350, P R China \\ ${ }^{2}$ Tianjin Key Laboratory of Composite and Functional Materials, School of Materials Science and \\ Engineering, Tianjin University, Tianjin 300350, P R China \\ *E-mail: jhwang@tju.edu.cn
}

doi: $10.20964 / 2019.01 .51$

Received: 5 October 2018 / Accepted: 10 November 2018 / Published: 30 November 2018

Erosion-corrosion behavior of an X65 steel reducer in oilfield formation water containing quartz sand particles was investigated using circulating loop system and scanning electron microscopy (SEM). The corrosion behavior of the X65 reducer during the erosion-corrosion was determined by electrochemical impedance spectroscopy (EIS), and the erosion behavior of the X65 reducer was simulated and calculated via computational fluid dynamic (CFD) method. By the synergistic interaction between erosion and corrosion, the pure corrosion rate, pure erosion rate, corrosion-enhanced erosion rate and erosion-enhanced corrosion rate of the typical reducer locations in the erosion-corrosion rate were quantified and compared. The experimental and simulation results indicated that with the decreasing of tube diameter the erosion-corrosion rate, erosion rate (total erosion rate, pure erosion rate and corrosionenhanced erosion rate) and their percentages in erosion-corrosion rate are increased. And the total corrosion rate and erosion-enhanced corrosion rate are also increased with the decreasing of tube diameter, but their percentages in erosion-corrosion rate are reduced. From the location of tube top, tube side to the tube bottom, a similar erosion-corrosion behavior could be obtained except for the reduction of corrosion-enhanced erosion rate and its percentage in erosion-corrosion rate. This erosion-corrosion behavior of the reducer is result from the distribution of flow velocity and sand particle concentration and the synergistic interaction between erosion and corrosion, especially the erosion-enhanced corrosion behavior.

Keywords: Erosion-corrosion, X65 steel, reducer, EIS spectrum, CFD simulation 
(C) 2019 The Authors. Published by ESG (www.electrochemsci.org). This article is an open access article distributed under the terms and conditions of the Creative Commons Attribution license (http://creativecommons.org/licenses/by/4.0/). 